\title{
IgA rheumatoid factor in the sera and saliva of patients with rheumatoid arthritis and Sjögren's syndrome
}

\author{
JAMES V. DUNNE, ${ }^{1}$ DENNIS A. CARSON, HANS L. SPIEGELBERG, \\ MARGARET A. ALSPAUGH, ${ }^{2}$ AND JOHN H. VAUGHAN
}

From the Division of Rheumatology, Department of Clinical Research and the Department of Immunopathology, Research Institute of Scripps Clinic, La Jolla, California 92037, USA

SUMMARY With a sensitive radioimmunoassay we have found elevated IgA rheumatoid factor (IgA-RF) levels in the sera of patients with rheumatoid arthritis, Sjögren's syndrome, and systemic lupus erythematosus. The IgA-RF showed a pattern of reaction with human IgG subclasses and animal gammaglobulins similar to that of IgM-RF from the same patients. Rheumatoid factors of both classes were shown to be present in saliva of patients with rheumatoid arthritis and Sjögren's syndrome.

Recently we have developed a solid phase radioimmunoassay for the measurement of IgM and IgG rheumatoid factors (Carson et al., 1977). Antiimmunoglobulins have been reported, however, to be present in the 3 major immunoglobulin classes (Heimer and Levin, 1966). IgA rheumatoid factor (IgA-RF) has been found in the sera (Torrigiani and Roitt, 1967; Panush, et al., 1971; Hallgren and Wilde, 1977), saliva (Heimer and Levin, 1966), and urine (Bienenstock et al., 1969) of selected patients with rheumatoid arthritis. The IgA-RF in most of these studies was measured as the quantity of serum IgA which bound to cross-linked rabbit or human IgG, and eluted under denaturing conditions. The eluted $\operatorname{IgA}$ was measured by radial immunodiffusion. These techniques have been difficult to reproduce, since contaminating IgM-RF can yield false positive reactions by precipitating with the developing antibodies used in the radial immunodiffusion (Lea and Ward, 1972).

In the present studies we have modified the above radioimmunoassay for the specific measurement of IgA-RF. With this method we determined IgA$\mathrm{RF}$ profiles, as well as IgM-RF, in sera and saliva from patients with rheumatoid arthritis, Sjögren's syndrome with rheumatoid arthritis, sicca syndrome,

Accepted for publication 3 May 1978

Correspondence to Dr J. V. Dunne. Present address: ${ }^{1}$ Department of Medicine, University of Ottawa, Ottawa, Ontario K1N 5C8, Canada. 'Department of Rheumatology, Louisiana State University Medical Center, New Orleans, Louisiana 70112 USA. and systemic lupus erythematosus. In selected specimens we also analysed the reactivity of IgARF with human IgG subclasses and animal gammaglobulins.

\section{Materials and methods}

\section{CLINICAL SPECIMENS}

Patients' sera were obtained from collections which had been frozen at $-20^{\circ} \mathrm{C}$. Sufficient sera were available for repeated studies of the following groups: 20 rheumatoid arthritis (RA) sera; 63 sera from patients with Sjögren's syndrome and rheumatoid arthritis (SSRA); 21 sera from patients with primary Sjögren's syndrome (SS); 15 systemic lupus erythematosus sera (SLE); 18 sera from patients admitted to hospital with diseases other than the above; and 10 normal sera. All these sera came from well characterised patients who have been subject to extensive investigations which have been previously reported (Alspaugh and Tan, 1975; Alspaugh et al., 1976; Vaughan et al., 1976).

Whole saliva was collected from 6 rheumatoid arthritis patients, 4 Sjögren's syndrome patients, and 4 with Sjögren's syndrome and rheumatoid arthritis. A serum sample was taken at the same time. The saliva was dialysed into borate buffered saline $0 \cdot 1 \mathrm{M} \mathrm{pH} 7 \cdot 2$ and stored at $-20^{\circ} \mathrm{C}$.

\section{PROTEINS}

Human, rabbit, and bovine IgG from Cohn fraction II (Sigma, St. Louis, Mo.) and a $40 \%$ 
ammonium sulphate cut of guinea-pig serum were further purified by DE52 chromatography. The preparations were shown to be immunologically pure by immunodiffusion. Human IgG (k) myeloma proteins of the 4 major heavy chain subclasses were prepared and typed by Dr Hans Spiegelberg.

\section{PREPARATIONS OF ANTIBODIES}

The method of preparation of rabbit antihuman IgM has been described previously (Carson et al., 1977), and the purification of the sheep anti-IgA was similar. Briefly, a $40 \%$ ammonium sulphate fraction of sheep antihuman IgA myeloma was digested to form $\mathrm{F}(\mathrm{ab})_{2}$ fragments by Nisonoff's (1964) method. The specific antihuman IgA antibody was eluted from a Sepharose-4B IgA myeloma affinity column and contaminating antibodies were removed on Sepharose-4B IgM and IgG columns.

Radioiodination of the antibodies was by the lactoperoxidase method of Marchalonis et al. (1971). After radioiodination the antibodies were again checked for cross reactivity and, if necessary, reabsorbed.

\section{RADIOIMM UNOASSAY}

This was performed as described previously (Carson et al., 1977). Briefly, duplicate $10 \times 75 \mathrm{~mm}$ plastic tubes (Falcon 2032, Oxnard, CA) were coated with $60 \mu \mathrm{g} / \mathrm{ml}$ intact heat-aggregated IgG in $0.9 \mathrm{ml}$ of $0.01 \mathrm{M}$ Tris, $0.15 \mathrm{M}$ saline, $\mathrm{pH} 7.4$ (Tris-saline) for 4 hours. The protein solution was aspirated off and the tubes rinsed and then quenched for 30 minutes with a Tris saline solution containing $1 \%$ bovine serum albumin (Tris-saline BSA). Then $1 \mathrm{ml}$ of a standard dilution of the sera or saliva to be tested was added and incubated overnight at $4^{\circ} \mathrm{C}$. The serum dilutions in Tris-saline-BSA were $1 / 200$ for IgARF estimations and $1 / 1000$ for IgM-RF. The saliva specimens were diluted $1 / 50$ for all estimations. The unbound material was aspirated and the tubes rinsed twice with Tris saline and incubated with about $10 \mathrm{ng}$ of ${ }^{125} \mathrm{I}$-anti-IgM or anti-IgA in $1 \mathrm{ml}$ Tris-saline-BSA. Specific activity of the antibody preparations varied from $10^{3}$ to $10^{4} \mathrm{cpm} / \mathrm{ng}$. Twentyfour hours later they were rinsed 3 times with Trissaline and counted.

\section{Results}

\section{SPECIFICITY OF THE RADIOIMMUNOASSAY}

Fig. 1 shows that only IgA and not IgG or IgM proteins inhibited the binding of ${ }^{125} \mathrm{I}-\operatorname{anti}-\mathrm{IgA}$ to $\mathrm{RF}$ coated tubes. The addition of aggregated human IgG (Fig. 2) at a concentration of $1 \mathrm{mg} / \mathrm{ml}$ inhibited binding by $>50 \%$. When serum globulins from a

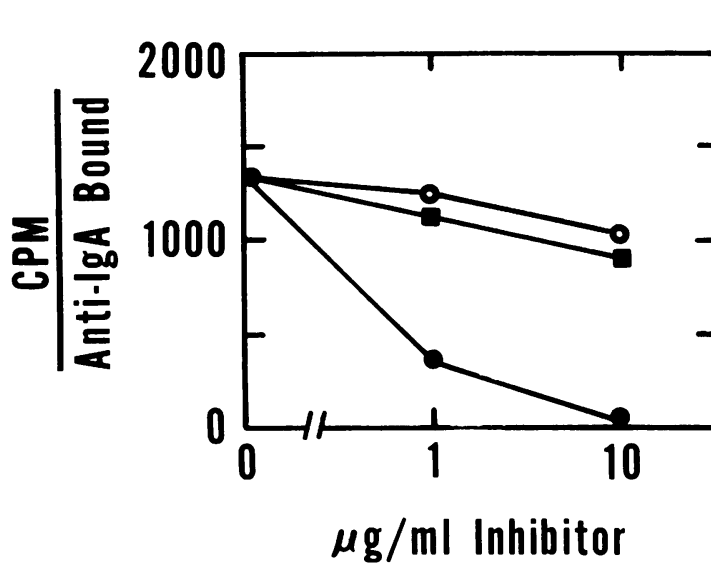

Fig. 1 Specificity of Anti-IgA antibody. $10 \times 75 \mathrm{~mm}$ plastic tubes were coated with $0.9 \mathrm{ml}$ of Tris saline buffer containing $60 \mu \mathrm{g} / \mathrm{ml}$ of human IgG. After a further 30 minutes' incubation with $0.1 \% B S A$ and washing, $0.9 \mathrm{ml}$ of a 1/200 dilution of a standard rheumatoid serum was added and incubated for 18 hours at $4^{\circ} \mathrm{C}$. The unbound material was removed and the tubes were washed twice with buffer. Radioiodinated anti-IgA antibody was then added in a volume of $1 \mathrm{ml}$ to which varying quantities of $\operatorname{Ig} M(0-0), \operatorname{Ig} G(\square-\square)$ and $\operatorname{IgA}\left(\mathrm{O}_{-} \mathrm{O}\right)$ were added. Eighteen hours later the tubes were washed 3 times with Tris-saline and the counts bound were determined. Only the addition of $\operatorname{Ig} A$ inhibited the binding of the antibody.

patient with RA were chromatographed on Sepharose-6B in neutral buffer, $\operatorname{IgA}$ binding activity? eluted at a position between the IgM and IgG markerso consistent with the pattern of an 11-S protein (results not shown). Thus the assay was specific for IgA antibodies reacting with human IgG.

REACTIVITY OF IGA-RF AND IGM-RF

WITH SUBCLASSES AND ANIMAL

GAMMAGLOBULINS

Table 1 compares the reactivity of IgA-RF and IgM-RF from selected RA sera with immunoglobulins of various animal species. As can be seen, both show the same cross-reactive pattern, binding best to human IgG, followed by rabbit, bovine, and guinea-pig IgG. Sera from two patients with Sjögren's syndrome with rheumatoid arthritis and one with Sjögren's syndrome without rheumatoid arthritis? showed similar cross-reactive patterns.

Table 2 shows the amount of IgA-RF and IgM-O웅 RF activity binding to IgG subclasses. As can be seen, IgA-RF shows the same binding patterns asp IgM-RF, reacting best with $\mathrm{IgG}_{1}$ protein, less welf with $\operatorname{IgG}_{4}$ and $\operatorname{IgG}_{2}$, and least well with $\operatorname{IgG}_{3}$. 


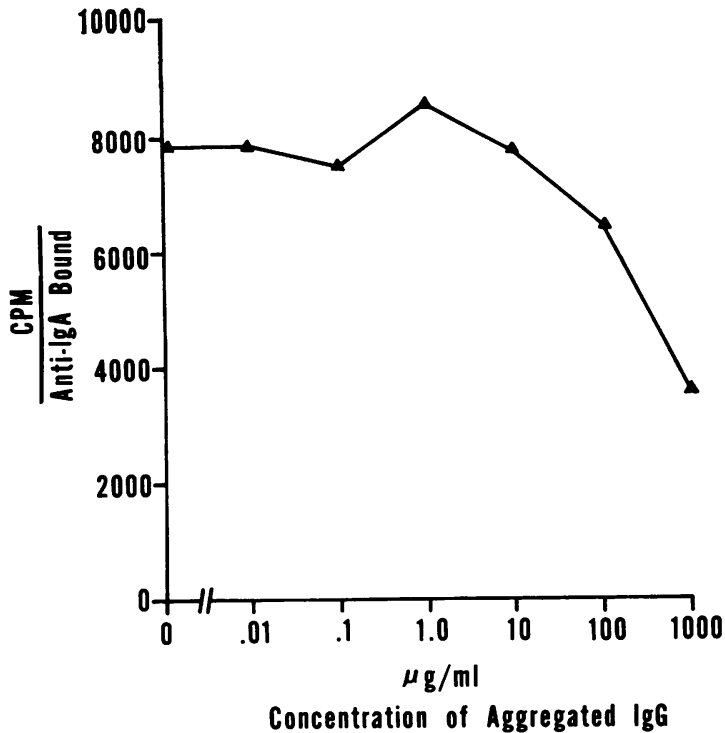

Fig. 2 Specificity of the assay for IgA-RF. To plastic tubes coated with IgG were added a 1/200 dilution of an $R A$ serum containing varying amounts of heat aggregated IgG. Eighteen hours later the tubes were washed and developed with $10^{5} \mathrm{cpm}$ of anti-IgA. After another 18 hours, the tubes were washed and counted.

Table 1 Reactivity of $\operatorname{Ig} A$ and IgM rheumatoid factors with animal gamma globulin.

\begin{tabular}{cllll}
\hline \multicolumn{5}{c}{$C P M$ bound $\pm S E M$} \\
\cline { 2 - 5 } & Human & Rabbit & Bovine & Guinea-pig \\
\hline $\begin{array}{c}\text { IgA-RF } \\
(\mathrm{n}=14)\end{array}$ & $2756 \pm 274$ & $2341 \pm 266$ & $2096 \pm 229$ & $962 \pm 101$ \\
$\begin{array}{c}\text { IgM-RF } \\
(\mathrm{n}=14)\end{array}$ & $7388 \pm 1563$ & $5741 \pm 759$ & $4292 \pm 661$ & $2299 \pm 1633$ \\
\hline
\end{tabular}

The assay was performed exactly as described in the 'Methods', using tubes coated with animal or human gammaglobulins, RA serum at a dilution of $1: 200$ (for IgA-RF) or 1:1000 (for IgM-RF) and 125I-anti IgA or anti-IgM as developing antibody. Background counts with bovine serum albumin-coated tubes were $<200 \mathrm{cpm}$ bound and are subtracted from the values shown.

Table 2 Reactivity of IgA and IgM rheumatoid factors with human IgG subclasses

\begin{tabular}{|c|c|c|c|c|}
\hline & \multicolumn{4}{|c|}{$C P M$ bound $\pm S E M$} \\
\hline & $I g G_{1}(k)$ & $\lg G_{2}(k)$ & $I g G_{3}(k)$ & $I g G_{4}(k)$ \\
\hline $\begin{array}{c}\text { IgA-RF } \\
(n=10) \\
\text { IgM-RF } \\
(n=10)\end{array}$ & $\begin{array}{r}1919 \pm 219 \\
30955 \pm 4697\end{array}$ & $\begin{array}{r}1431 \pm 224 \\
24066 \pm 4793\end{array}$ & $\begin{array}{r}1017 \pm 182 \\
315014 \pm 3836\end{array}$ & $\begin{array}{r}1814 \pm 229 \\
22789 \pm 4519\end{array}$ \\
\hline
\end{tabular}

This assay was performed as described in Table 1 except that the tubes were coated with purified human myeloma proteins from each IgG subclass. In addition the specific activity of the antibodies used for development differed, so that the absolute number of counts bound in the 2 experiments cannot be compared.

\section{LEVELS OF IGA-RF IN SERA}

Fig. 3 shows the relative amounts of IgA-RF in sera from patients with rheumatoid arthritis, Sjögren's syndrome with rheumatoid arthritis, Sjögren's syndrome without rheumatoid arthritis, and systemic lupus erythematosus, as compared to normal controls analysed on the same day. As can be seen, all patient groups had significantly elevated levels of IgA-RF activity $(\mathrm{P}<0 \cdot 01)$.

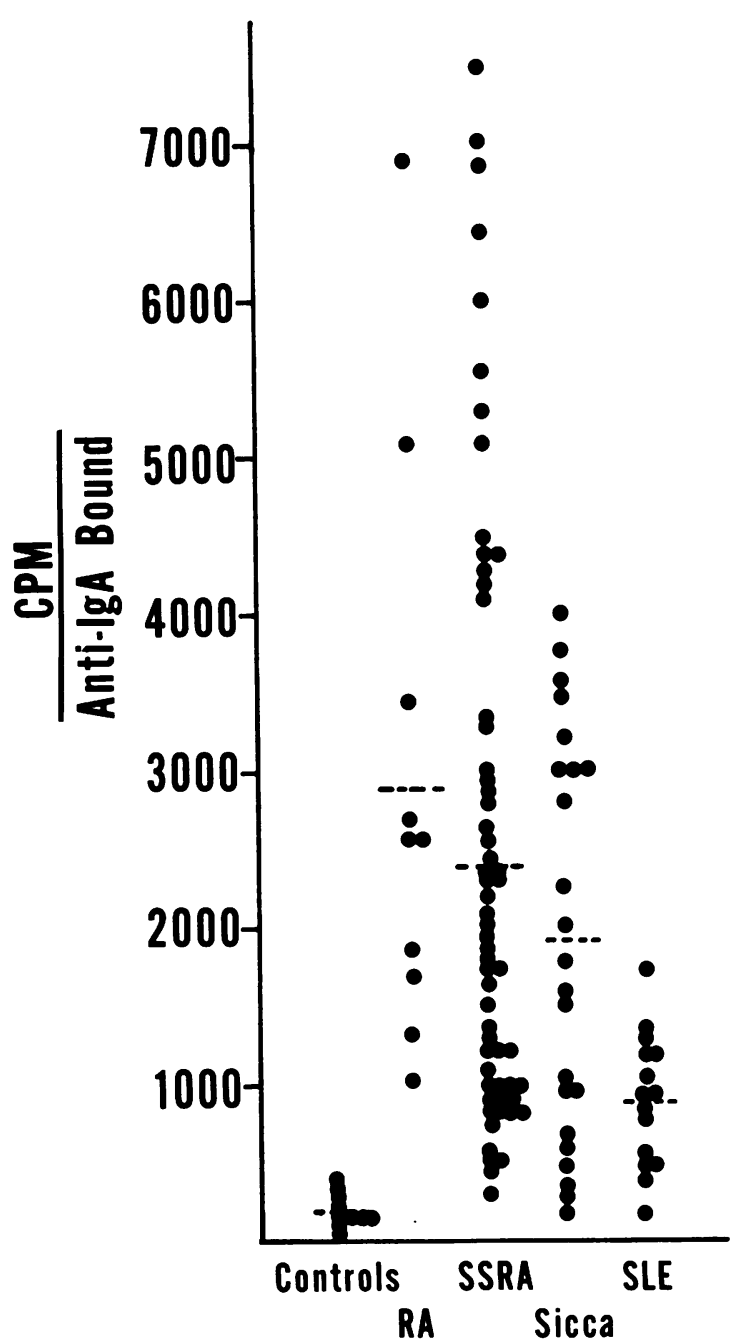

Fig. 3 Serum IgA-RF in patient groups. This experiment compares levels of IgA-RF in the sera of the patients with rheumatoid arthritis $(R A)$, Sjögren's syndrome with RA (SSRA) sicca syndrome without synovitis (SS), and systemic lupus erythematosus (SLE). The dotted lines show the mean values of the various groups. 
IgA-RF IgM-RF

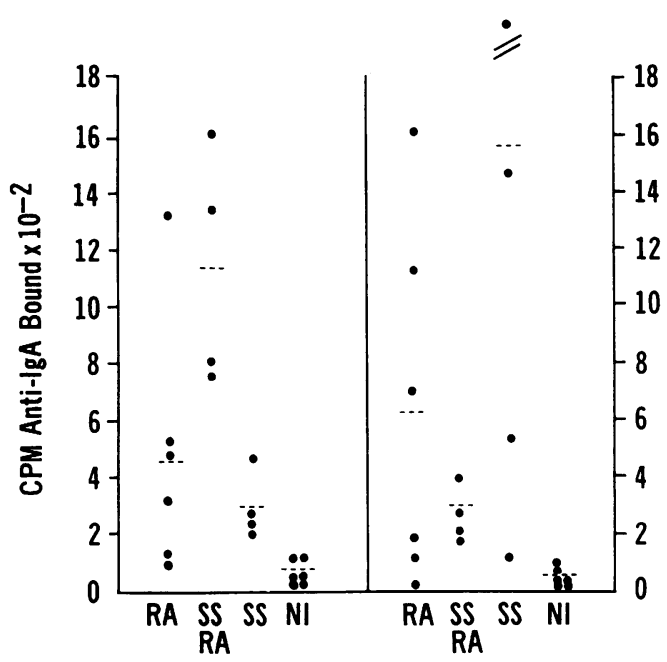

Fig. 4 Salivary IgM-RF and $\operatorname{Ig} A-R F$ in rheumatoid arthritis $(R A)$, Sjögren's syndrome (SS), and normal individuals (NI). This experiment was performed as described in Fig. 3, except that saliva was substituted for serum.

\section{LEVELS OF RF IN SALIVA}

Fig. 4 shows the increased amounts of IgM-RF and IgA-RF in the saliva of patients with rheumatoid arthritis (RA), Sjögren's syndrome (SS), and Sjögren's syndrome with rheumatoid arthritis (SSRA) as compared to normal controls.

In other experiments salivary IgM-RF levels showed a correlation coefficient of 0.77 when compared with IgM-RF activity in the serum, while salivary and serum IgA-RF levels had a correlation coefficient of $0 \cdot 51$.

\section{Discussion}

In this study we have described a radioimmunoassay which specifically measures IgA-RF reacting with human IgG. With this method rheumatoid arthritis patients, both with and without Sjögren's syndrome, as well as patients with primary Sjögren's syndrome were shown to have raised levels of $\operatorname{IgA}-\mathrm{RF}$ in serum and saliva. The binding patterns of IgA-RF and IgM-RF in the sera of patients with rheumatoid arthritis and Sjögren's syndrome were similar. Each reacted best with $\operatorname{IgG}_{1}$ myeloma proteins followed by those of the $\mathrm{IgG}_{4}, \mathrm{IgG}_{2}$, and $\mathrm{IgG}_{3}$ classes. Abraham et al. (1972) have found similar immunochemical properties in a single 7-S IgA myeloma protein with rheumatoid factor activity. IgA-RF shows cross-reactivity with animal gammaglobulins similar to that of IgM-RF.

The presence of IgA and IgM autoantibodies with $\vec{\nexists}$ similar properties in these patients is of interest $\stackrel{0}{+}$ because it suggests not only that the autoantibody $\frac{}{c}$ response in rheumatoid disease is polyclonal, but $\overline{\bar{T}}$ also that the switch mechanism from IgM to $\operatorname{IgA} \frac{\sqrt{5}}{\vec{D}}$ immunoglobulin production is intact for this auto- $\triangle$ antibody. Since IgA antibody formation is probably o T-cell dependent (Lamm, 1975) this result suggests $\vec{\circ}$ a role for helper $\mathrm{T}$ cells in the induction of autoantibody.

By radioimmunoassay we found elevated levels of IgA-RF and IgM-RF in the saliva of rheumatoid and Sjögren's syndrome patients. Helmer and Levin $\omega_{\infty}$ (1966) have previously found IgA-RF in rheumatoid iv saliva, but were unable to detect IgM-RF. On the $\vec{\sigma}$ other hand Talal et al. (1970), using immunoprecipitation and autoradiography of supernatants from cultured salivary glands of patients with Sjögren's syndrome, showed evidence of IgM-RF but $\frac{7}{0}$ not IgA-RF activity. That we could consistently detect RF in both immunoglobulin classes in the $\overrightarrow{0}$ saliva is a reflection of the greater sensitivity of the 6 radioimmunoassay method.

Serum and salivary IgM-RF activities were more closely correlated than were the corresponding IgA-RF levels. Thus, while most salivary IgM-RF probably derives from serum, some IgA-RF may be produced locally. Whether or not IgA-RF contribute to the damage which occurs in the salivary glands in these patients is unclear. Other IgA antibodies have been shown to fix complement via the alternate pathway (Gotze et al., 1971), but this has not been shown for $\operatorname{IgA}$ autoantibodies showing rheumatoid factor activity. In summary, a sensitive solid-state radioimmunoassay which measures both IgM and IgG-RF activity has now been extended $\delta$ to measure IgA-RF activity in both serum and saliva.

We thank Ms Mary Pat McNally for her excellent technical assistance and Drs Dan Small and Manuel Martinez-Lavin $\frac{D}{O}$ and the staff of the GCRC for their help. Sera and saliva were provided by Dr J. H. Vaughan and Dr E. Tan. Grateful N appreciation is due to Mrs Anna Milne and Mrs Alison Drewette who helped with the manuscript.

This work was supported in part by NIH Grants CA 14126, RR 00833, AM 00369, RR 05514, and a grant from $\omega$ the Kroc Foundation.

\section{References}

Abraham, G. N., Clark, A. R., and Vaughan, J. H. (1972). Characterization of an IgA rheumatoid factor: binding properties and reactivity with the sub-classes of human gamma-G globulin. Immunochemistry, 9, 301-315.

Alspaugh, M. A., and Tan, E. M. (1975). Antibodies to cellular antigens in Sjögren's Syndrome. Journal of Clinical Investigation, 55, 1067-1073. 
Alspaugh, M. A., Talal, N., and Tan, E. M. (1976). Differentiation and characterization of autoantibodies and their antigens in Sjögren's Syndrome. Arthritis and Rheumatism, 19, 216-222.

Bienenstock, J., Goldstein, G., and Tomasi, T. B. (1969). Urinary $\gamma$ A rheumatoid factor. Journal of Laboratory and Clinical Medicine, 73, 389-398.

Carson, D. A., Lawrence, S., Abraham, G., Catalano, M. and Vaughan, J. H. (1977). Radio-immunoassay of IgG and IgM rheumatoid factors reacting with human IgG. Journal of Immunology, 119, 295-300.

Gotze, O., and Muller-Eberhard, H. J. (1971). The $C_{3}$ activator system: an alternate pathway of complement activation. Journal of Experimental Medicine, 134, Supplement 90 s-108s.

Hallgren, R., and Wilde, L. (1977). Precipitation of ${ }^{125} \mathrm{I}-$ labelled IgG aggregates by factors in sera of healthy individuals and of patients with rheumatoid arthritis. Annals of the Rheumatic Diseases, 36, 21-29.

Heimer, R., and Levin, F. W. (1966). On the distribution of rheumatoid factors among the immunoglobulins. Immunochemistry, 3, 1-10.

Lamm, M. E. (1975). Cellular aspects of immunoglobulin A. Advances in Immunology, 17, 223-290.
Lea, D. J. and Ward, D. J. (1972). The quantitation of rheumatoid factors. Arthritis and Rheumatism, 15, 646648.

Marchalonis, J. J., Cone, R. E. and Santer, U. (1971) Enzymic iodination. Biochemical Journal, 124, 921-927.

Nisonoff, A. (1964). Enzymatic digestion of rabbit gamma globulin and antibody and chromatography of digestion products. Methods in Medical Research, 10, 134-141

Panush, R. S., Bianco, N. E., and Schur, P. H. (1971). Serum and synovial fluid IgG, IgA and IgM anti gammaglobulins in rheumatoid arthritis. Arthritis and Rheumatism, 14, 737-747.

Talal, N., Asofsky, R., and Lightbody, P. (1970). Immunoglobulin synthesis by salivary gland lymphoid cells in Sjögren's syndrome. Journal of Clinical Investigation, 49, 49-54

Torrigiani, G., and Roitt, I. M. (1967). Antiglobulin factors in sera from patients with rheumatoid arthritis and normal subjects. Annals of the Rheumatic Diseases, 26, 334-340.

Vaughan, J. H., Chihara, T., Moore, T. L., Robbins, D. L., Tanimoto, K., Johnson, J. S. and McMillan, R. (1976). Rheumatoid factor-producing cells detected by direct hemolytic plaque assay. Journal of Clinical Investigation, 58, 933-941. 